\title{
Chromosome-pairing in trisomic spermatocytes of males with normal or altered karyotypes
}

\author{
M Świtoński ${ }^{1}$, G Stranzinger ${ }^{2}$, PK Basrur ${ }^{3}, R_{\text {RM Kenney }}{ }^{4}$ \\ 1 Academy of Agriculture, Wolynńska 33, Pl-60-637 Poznań, Poland; \\ ${ }^{2}$ Federal Institute of Technology, Tannenstr 1, CH-8092 Zürich, Switzerland; \\ 3 University of Guelph, Ontario Veterinary College, Guelph, Ontario N1G 2W1, Canada; \\ 4 University of Pennsylvania, New Bolton Center, PA 19348, USA
}

(Proceedings of the 9th European Colloquium on Cytogenetics of Domestic Animals; Toulouse-Auzeville, 10-13 July 1990)

meiosis / synaptonemal complexes / aneuploidy / trisomy / domestic animals

\section{INTRODUCTION}

Chromosome studies carried out in domestic mammals show that aneuploidy is rare compared to structural chromosomal aberrations. Among the cases of aneuploidy reported, the most frequent is the monosomy XO syndrome in mares (Cribiu, 1984; Long, 1988). There are also identified cases of trisomy $\mathrm{X}$ in cows (Pinheiro et al, 1987), the XXY syndrome in bulls (Sysa and Słota, 1984) and autosomal trisomics (Herzog et al, 1977; Mäkinen et al, 1987; Klunder et al, 1989).

The low frenquency of aneuploidy in domestic mammals is attributable to several factors. Aneuploidy often causes lethality or major malformations affecting the viability of carriers. Malformed animals are, therefore, usually culled by breeders without recourse to cytogenetic investigation. If animals carrying aneuploid karyotypes are viable, they are often sterile. Unlike structural rearrangements which are inherited, this type of chromosomal aberration cannot be spread in a population due to the sterility of the carriers. Therefore, it is safe to assume that all identified cases of aneuploidy were of de novo origin.

In the present study, we show that, among germ cells of the males with normal and altered karyotypes, trisomic spermatocytes can occur regardless of the somatic chromosome constitution of the animal. 


\section{MATERIALS AND METHODS}

The samples of testicular tissue were collected from 3 males with recognized karyotypes: 1) a normal bull, $60, \mathrm{XY} ; 2$ ) a stallion diagnosed as being sterile, $64, \mathrm{XY}$; and 3) a balanced Robertsonian translocation-carrier goat buck, 59,XY rob (3/7).

Analyses of synaptonemal complexes were carried out by the application of the 'whole mount' surface spreading technique (Counce and Meyer, 1973). The analytical procedure described by Świtoński et al (1987) was followed.

Spermatocytes were observed with Philips 210 and Joel 100S electron microscopes.

\section{RESULTS}

Altogether, 79 primary spermatocytes were examined for synaptonemal complexes (table I). Among these, 22, 33 and 24 cells were from the bull, the stallion and the buck, respectively. In each of these animals, one spermatocyte was noted to be trisomic, representing $4.5,3.0$ and $4.2 \%$ of the total number of spermatocytes analyzed from these 3 animals, respectively.

Table I. Occurrence of trisomic spermatocytes.

\begin{tabular}{llcc}
\hline \multirow{2}{*}{ Animal } & Karyotype & \multicolumn{2}{c}{ Number of spermatocytes } \\
\cline { 3 - 4 } & & total & trisomic spermatocytes \\
\hline Bull & $60, \mathrm{XY}$ & 22 & 1 \\
Stallion & $64, \mathrm{XY}$ & 33 & 1 \\
Buck & $59, \mathrm{XY}$ rob $(3 / 7)$ & 24 & 1 \\
\hline
\end{tabular}

In the case of the bull, the trivalent detected in the trisomic spermatocyte was medium-sized (fig 1). One of these chromosomes was partly aligned with the completely synapsed bivalent. However, the central element between the bivalent and the third chromosome was not detectable. The third chromosome was thicker and had a stranded appearance typical of the unpaired chromosomal segments.

The trivalent found in the sterile stallion represented a small-sized acrocentric chromosome (fig 2). A combination of pairing possibilities was illustrated by this trivalent. The middle part of the trivalent showed triple pairing with 2 parallel central elements. At both distal ends, 2 out of 3 lateral elements were synapsed, while the third one remained unpaired. Again, the unpaired segments were thicker and stranded, as described above for the bull's trivalent. In addition, in some parts of this trivalent, all 3 lateral elements also remained unpaired.

The trivalent found in the buck's spermatocyte was relatively short (fig 3 ), it had an even contour and a regular appearance and all lateral elements were completely paired along the whole trivalent. 

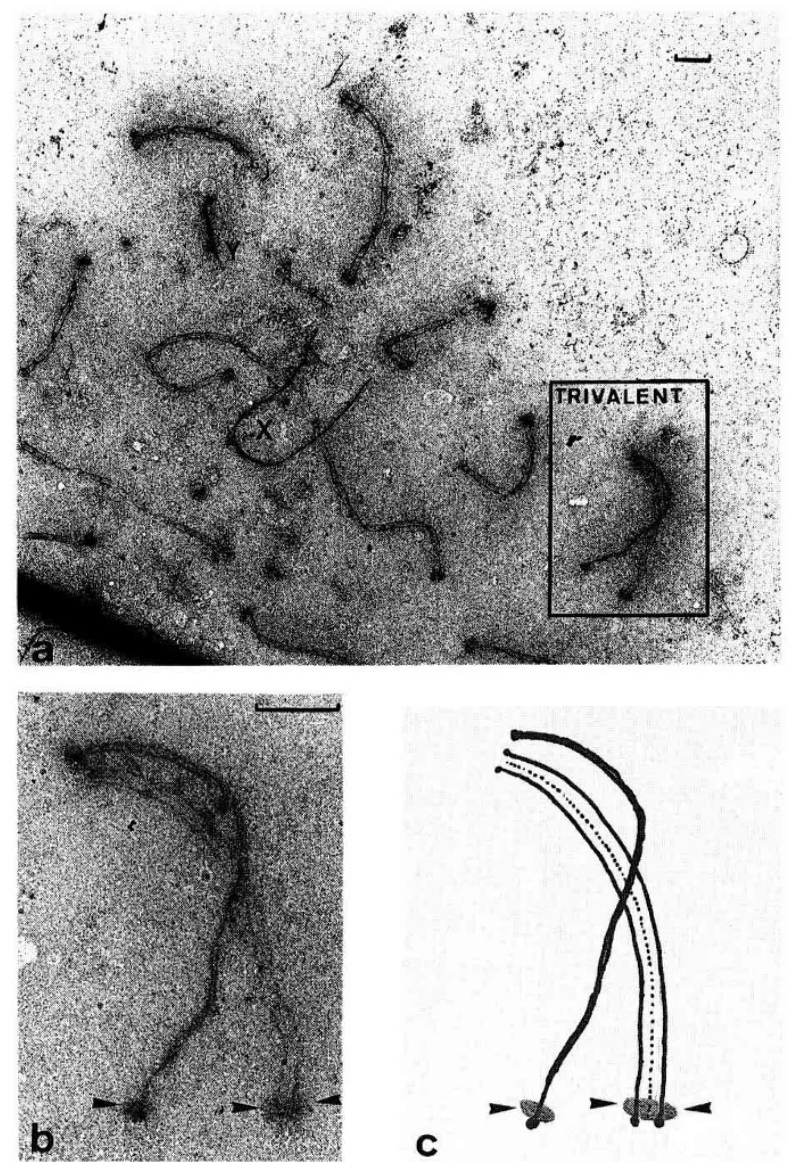

Fig 1. Trivalent configuration in a spermatocyte from the normal bull 60,XY. a. Part of the primary spermatocyte, the trivalent and the sex chromosomes are indicated. $\mathbf{b}$. The trivalent at higher magnification. c. Schematic drawing of the trivalent. Arrowheads show the positions of kinetochores. Bars represent $1 \mu \mathrm{m}$.

\section{DISCUSSION}

On the basis of the present observations on trisomic spermatocytes, it can be surmised that chromosomal non-disjunction occurred in spermatogonia of the animals investigated at a frequency of up to $4.5 \%$. Spontaneous occurrence of trisomic spermatocytes has also been described by other authors. Dollin and Murray (1984) reported one trisomic spermatocyte among the 16 cells analyzed (6.2\%) in a bull. Analyses of synaptonemal complexes in Sitka deer mouse (Hale and Greenbaum, 1986) showed 7 trisomic spermatocytes with an XXY set among 422 cells $(1.6 \%)$ studied from 3 animals. The above-mentioned studies on the spontaneous occurrence of trisomic spermatocytes and the observed frequency 

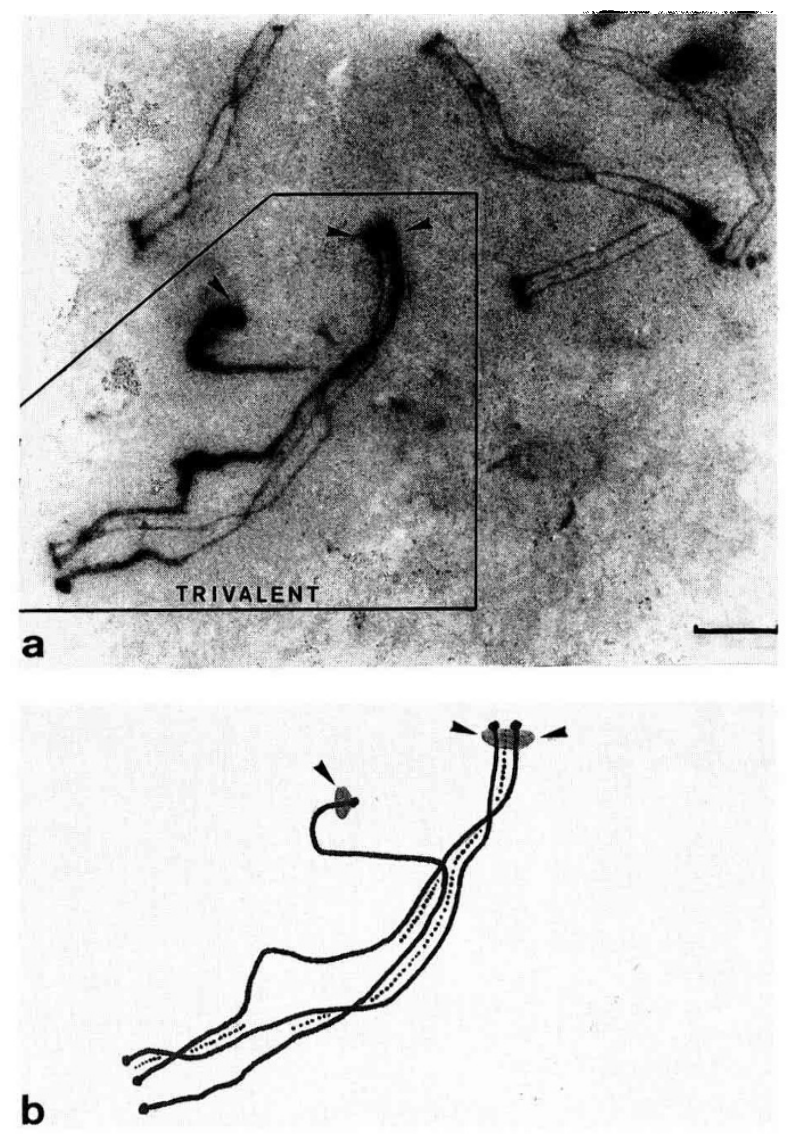

Fig 2. Trivalent configuration in a spermatocyte from the infertile stallion $64, \mathrm{XY}$. a. Part of the primary spermatocyte, the trivalent is indicated. b. Schematic drawing of the trivalent. Arrowheads indicate the positions of kinetochores. Bar represents $1 \mu \mathrm{m}$.

of such events ranging from 1.6 to $6.2 \%$ are in agreement with the finding of a recent investigation on the frequency of aneuploidy in human sperm (Martin and Rademaker, 1990). These authors found that the overall frequency of aneuploidy was $3.9 \%$, however, cases of hypohaploid sperm were more frequent $(3.3 \%)$ than the hyperhaploid ones $(0.7 \%)$.

Pairing behavior of trivalents in a trisomic situation can vary considerably. In our study, we found a variety of pairing behaviors: 1) an alignment of the third chromosome along the synapsed bivalent without forming a central element, 2) partial pairing between all 3 partners with formation of central elements between 2 or 3 lateral elements, and 3 ) complete triple pairing forming 2 parallel central elements. A varied pairing behavior of trivalents was also observed in studies on synaptonemal complexes in carriers of autosomal trisomy in a human female fetus (Wallace and Hulten, 1983) and a stallion (Power et al, unpublished). In the latter 

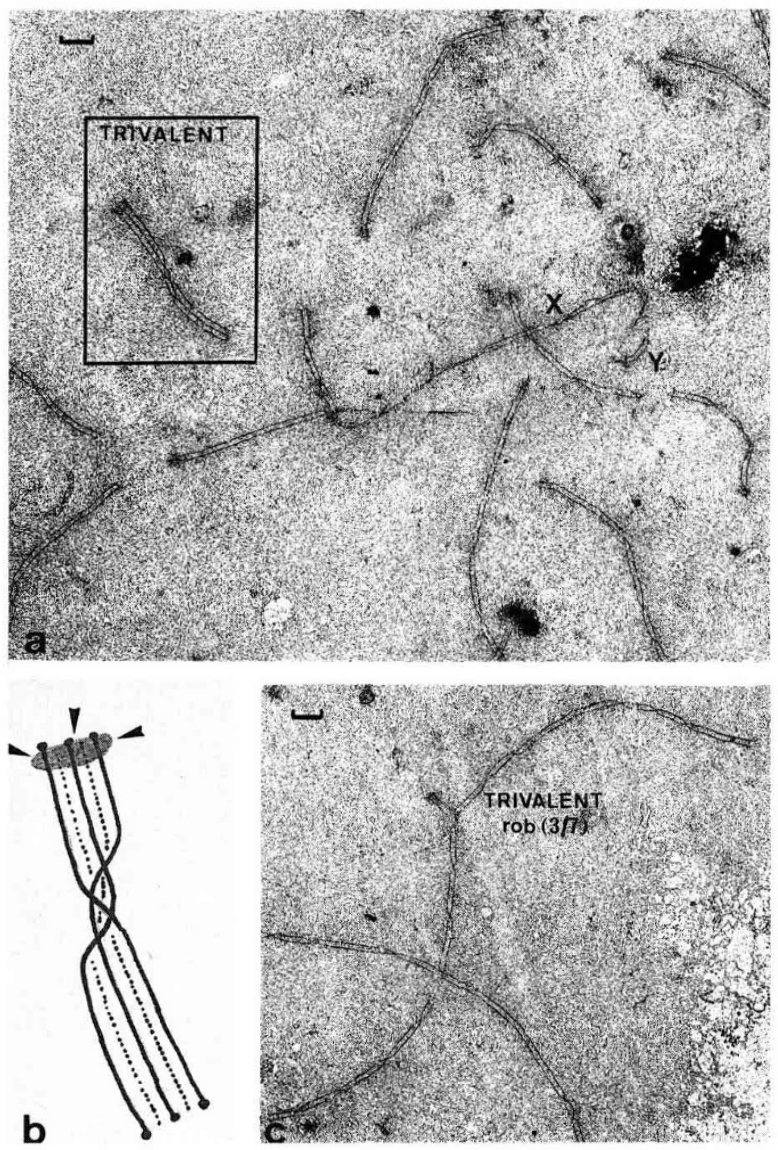

Fig 3. Trivalent configuration in a spermatocyte from the buck heterozygous for a Robertsonian translocation $59, \mathrm{XY} \operatorname{rob}(3 / 7)$. a. Part of the primary spermatocyte, the trivalent and the chromosomes are indicated. b. Schematic drawing of the trisomic trivalent. Arrowheads indicate the positions of kinetochores. c. Robertsonian trivalent from the same spermatocyte. Bars indicate $1 \mu \mathrm{m}$.

study, the trivalent very often (in $50 \%$ of observed cells) was associated or paired with the sex bivalent.

Identification of non-disjunction events at different levels of gametogenesis can improve our knowledge on the mechanisms responsible for the occurrence of chromosomally unbalanced gametes and embryos. The spontaneous occurrence of trisomic primary spermatocytes shows in our animals and those discussed above that chromosomal non-disjunction in spermatogonia plays an important role in this process. 


\section{REFERENCES}

Counce SJ, Meyer GF (1973) Differentiation of the synaptonemal complex and the kinetochore in Locusta spermatocytes studied by whole mount electron microscopy. Chromosoma 44, 231-253

Cribiu EP (1984) Quelques cas de dysgénésie gonadique chez la jument causés par différentes aberrations gonosomiques (monosomie $\mathrm{X}$, mosaique $\mathrm{X} / \mathrm{XX}$ et caryotype $\mathrm{XY}$ ). Génét Sél Evol 16, 397-404

Dollin AE, Murray JD (1984) Triple chromosome pairing in an aneuploid bull spermatocyte. Can J Genet Cytol 26, 782-783

Hale DW, Greenbaum IF (1986) Spontaneous occurrence of XXY primary spermatocytes in the Sitka deer mouse. J Hered 77, 131-132

Herzog A, Hohn H, Rieck GW (1977) Survey of recent situation of chromosome pathology in different breeds of German cattle. Ann Génét Sel Anim 9, 471-491

Klunder LR, McFeely RA, Beech J, McClune W, Bilinski WF (1989) Autosomal trisomy in a standard bred colt. Equine Vet $J 21,69-79$

Long SE (1988) Chromosome anomalies and infertility in the mare. Equine Vet $J$ 20, 89-93 Mäkinen A, Alitalo I, Alanco M (1987) Autosomal trisomy in a heifer. Acta Vet Scand 28, $1-8$

Martin RH, Rademaker A (1990) The frequency of aneuploidy among individual chromosomes in 6821 human sperm chromosome complements. Cytogenet Cell Genet 53, 103-107 Pinheiro LEL, Almeida IL, Garcia JN, Basrur PK (1987) Trisomy X and 1/29 translocation in infertile heifers. Theriogenetics $28,891-898$

Świtoński M, Gustavsson 1, Plöen L (1987) The nature of the $1 ; 29$ translocation in cattle as revealed by synaptonemal complex analysis using electron microscopy. Cytogenet Cell Genet 44, 103-111

Sysa PS, Slota E (1984) The XXY syndrome in cattle. 6th European Colloquium on Cytogenetics of Domestic Animals (Zurich). (Sranzinger G, ed) 120-128

Wallace GMN, Hulten MA (1983) Triple chromosome synapsis in oocytes from a human fœtus with trisomy 21. Ann Hum Genet 47, 271-276 